\title{
Bio-Optical Characteristics of the Black Sea Coastal Waters near Sevastopol: Assessment of the MODIS and VIIRS Products Accuracy
}

\author{
E. Yu. Skorokhod ${ }^{1, 凶}$, T. Ya. Churilova ${ }^{1}$, T. V. Efimova ${ }^{1}$, \\ N. A. Moiseeva ${ }^{1}$, V. V. Suslin ${ }^{2}$ \\ ${ }^{1}$ A. O. Kovalevsky Institute of Biology of the Southern Seas, Russian Academy of Science, \\ Sevastopol, Russian Federation \\ ${ }^{2}$ Marine Hydrophysical Institute of RAS, Sevastopol, Russian Federation \\ 凶elenaskorokhod@ibss-ras
}

\begin{abstract}
Purpose. The purpose of the work is to evaluate accuracy of the satellite products for the coastal waters near Sevastopol, generated by the standard algorithms based on the MODIS and VIIRS (installed at the artificial Earth satellites Aqua and Terra, and at Suomi NPP, respectively) data.

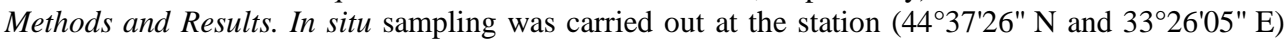
located at a distance of two miles from the Sevastopol Bay. The chlorophyll $a$ concentration was measured by the spectrophotometric method. The spectral light absorption coefficients by optically active components were measured in accordance with the current NASA protocol. The spectroradiometers MODIS and VIIRS Level-2 data with spatial resolution $1 \mathrm{~km}$ in nadir around the in situ station $\left(44^{\circ} 37^{\prime} 26^{\prime \prime} \pm 0^{\circ} 00^{\prime} 32^{\prime \prime} \mathrm{N}\right.$ and $\left.33^{\circ} 26^{\prime} 05^{\prime \prime} \pm 0^{\circ} 00^{\prime} 54^{\prime \prime} \mathrm{E}\right)$ were used. The satellite products were processed by the SeaDAS 7.5.3 software developed in NASA. The research showed that the standard NASA algorithms being applied to the MODIS and VIIRS data, yielded incorrect values of the optically active components' content in the Black Sea coastal waters near Sevastopol as compared to the data of in situ measurements in the same region: the satellite-derived "chlorophyll $a$ concentration" was on average 1.6 times lower in spring, and 1.4 times higher in summer; the contribution of phytoplankton to total light absorption at $443 \mathrm{~nm}$ was underestimated in 8.7 times; the light absorption by colored detrital matter was overestimated in 2.2 times.

Conclusions. The NASA standard algorithms are inapplicable to calculating bio-optical indices in the coastal waters of the Black Sea near Sevastopol since they provide incorrect values of the satellite products ( $C_{a-\mathrm{s}}, a_{\mathrm{ph}-\mathrm{s}}(443)$ and $\left.a_{\mathrm{CDM}-\mathrm{s}}(443)\right)$. Operative ecological monitoring based on satellite data requires development of a regional algorithm taking into account the seawater optical features in the region and in the coastal zone, in particular.
\end{abstract}

Keywords: chlorophyll $a$, phytoplankton, colored dissolved organic matter, non-algal particles, remote sensing, MODIS, VIIRS, Black Sea

Acknowledgments: the investigation was carried out within the framework of the state task on theme No. AAAA-A19-119061190081-9 and at the RFBR financial support of project No. 18-45-920070. The authors are very thankful to the junior researcher E. G. Sakhon and the leading engineer E. A. Zemlianskaia (IBSS, Sevastopol) for their assistance in sampling during regular bio-optical monitoring in the Sevastopol Bay. The authors are grateful to Goddard Space Flight Center and Ocean Biology Processing Group (NASA) for the data provided and their preliminary processing.

For citation: Skorokhod, E.Yu., Churilova, T.Ya., Efimova, T.V., Moiseeva, N.A. and Suslin, V.V., 2021. Bio-Optical Characteristics of the Black Sea Coastal Waters near Sevastopol: Assessment of MODIS and VIIRS Products Accuracy. Physical Oceanography, [e-journal] 28(2), pp. 215-227. doi:10.22449/1573-160X-2021-2-215-227

DOI: 10.22449/1573-160X-2021-2-215-227

(C) E. Yu. Skorokhod, T. Ya. Churilova, T. V. Efimova, N. A. Moiseeva, V. V. Suslin, 2021

(C) Physical Oceanography, 2021 


\section{Introduction}

Remote sensing is actively applied to solve various scientific problems, including operational monitoring of the aquatic ecosystems state. Great advantages of remote sensing are the ability to carry out long-term series of observations with a large spatial coverage.

In aquatic ecosystems, coastal waters deserve distinct consideration, since they are heavily impacted by man-made factors. With river/coastal runoff, suspended and colored dissolved organic matter along with nutrients enters coastal waters, which leads to phytoplankton biomass increase in coastal waters [1]. Phytoplankton, nonalgal particles and colored dissolved organic matter are optically active components of the environment (OAC). The OAC content in water and their spectral optical properties (absorption and scattering) [2-4] determine the radiance ascending from the water column, recorded by satellite instruments [5]. The variability of OAC contribution to the total light absorption is one of the reasons for the inaccuracy of modeling satellite products using standard algorithms.

Chlorophyll $a$ concentration $\left(C_{a-s}\right)$ is one of the standard satellite products used widely as water productivity indicator. To use satellite products, it is important to verify that they characterize the studied water area state correctly. At present, no works with the results of the MODIS and VIIRS satellite products comparison with in situ measurements in the coastal Black Sea waters in different seasons of the year similar in space and time are known.

Long-term data array of regular bio-optical monitoring carried out in the coastal Black Sea waters in the Sevastopol Bay area since 2009 is a unique base for satellite data validation.

The purpose of the present work is to evaluate accuracy of the satellite products for the coastal waters near Sevastopol, generated by the standard algorithms based on the MODIS and VIIRS (installed at the artificial Earth satellites Aqua ${ }^{1}$ (MA) and Terra $^{2}(M T)$, and VIIRS ${ }^{3}$ at Suomi NPP (V) respectively) data. For this purpose, a comparison between the chlorophyll $a$ concentration of and the light absorption coefficient of the OAC, calculated from satellite and in situ data in the coastal waters of Sevastopol in individual seasons was carried out.

Preliminary results were presented at the All-Russian Scientific Conference [6].

\section{The Material and Methods}

The in situ data. As part of regular bio-optical monitoring, samples were taken in the surface layer of the Black Sea at a station located opposite Sevastopol Bay at a distance of two miles from the coast at $44^{\circ} 37^{\prime} 26$ "N, $33^{\circ} 26^{\prime} 05^{\prime \prime}$ E point. The depth at the station is $\sim 62 \mathrm{~m}$.

To determine the chlorophyll $a$ concentration $\left(C_{a-\mathrm{i}}\right)$, a spectrophotometric method was used [7]. Light absorption by particles $\left(a_{\mathrm{p}-\mathrm{i}}(\lambda)\right)$ and colored dissolved organic matter $\left(a_{\text {CDOM-i }}(\lambda)\right)$ were measured in accordance with the NASA protocol $[8,9]$. Seawater samples were gently vacuum filtered (no more than $0.2 \mathrm{~atm}$ ) onto $25 \mathrm{~mm}$

\footnotetext{
${ }^{1}$ NASA Goddard Space Flight Center, 2020. Ocean Color WEB. [online] Available at: https://oceancolor.gsfc.nasa.gov/data/aqua/ [Accessed: 21 October 2020].

${ }^{2}$ NASA Goddard Space Flight Center, 2020. Ocean Color WEB. [online] Available at: https://oceancolor.gsfc.nasa.gov/data/terra/ [Accessed: 21 October 2020].

${ }^{3}$ NASA Goddard Space Flight Center, 2020. Ocean Color WEB. [online] Available at: https://oceancolor.gsfc.nasa.gov/data/viirs-snpp/ [Accessed: 21 October 2020].
} 
diameter GF/F type (Whatman) glass fiber filters with pores of $0.7 \mu \mathrm{m}$. To obtain a sample of the colored dissolved organic matter, seawater was passed through $47 \mathrm{~mm}$ diameter membrane filters with pores of $0.2 \mu \mathrm{m}$.

Spectrophotometric measurements were carried out immediately after sampling on dual-beam spectrophotometers: SPECORD M40 (Carl Zeiss Jena) in 2009-2014 and LAMBDA 35 (PerkinElmer) with an integrating sphere in 2015-2019.

Light absorption by particles $\left(a_{\mathrm{p}-\mathrm{i}}(\lambda)\right)$ was divided into absorption by phytoplankton $\left(\left(a_{\mathrm{ph}-\mathrm{i}}(\lambda)\right)\right.$ and absorption by non-algal particles $\left(a_{\mathrm{NAP}-\mathrm{i}}(\lambda)\right)$ in-accordance with the general methods $[10,11]$.

Satellite data. MODIS and VIIRS Level- $2^{4}$ data with a spatial resolution of $1 \mathrm{~km}$ were used.

The following satellite products were used in the analysis:

- chlorophyll $a$ concentration $\left(C_{a-s}, \mathrm{mg} \cdot \mathrm{m}^{-3}\right)$, generated based on two standard NASA algorithms: Ocean chlorophyll algorithm (OCx) [12] and Hu color index (CI) [13];

- light absorption by phytoplankton at $443 \mathrm{~nm}\left(a_{\mathrm{ph}-\mathrm{s}}(443), \mathrm{m}^{-1}\right)$, generated according to the NASA Generalized Inherent Optical Property (GIOP) model $[14,15]$;

- light absorption by colored detrital matter (colored dissolved organic matter and non-algal particles) at $443 \mathrm{~nm}\left(a_{\mathrm{CDM}-\mathrm{s}}(443), \mathrm{m}^{-1}\right)$, generated according to the NASA GIOP model.

Satellite data processing was carried out using SeaDAS 7.5.3 software developed by NASA ${ }^{5}$. Satellite data was sampled from the area around the station. The area is in square-shaped centered at $44^{\circ} 37^{\prime} 26^{\prime \prime} \pm 0^{\circ} 00^{\prime} 32^{\prime \prime} \mathrm{N}$ and $33^{\circ} 26^{\prime} 05^{\prime \prime} \pm 0^{\circ} 00^{\prime} 54^{\prime \prime E}$. When selecting satellite data, preference was given to those geographically close to the point of field measurements. In the absence of satellite data in the selected area, standard products were obtained by approximating the values of neighboring pixels (at least two adjacent pixels from opposite sides).

\section{Results and Discussion}

Comparison of satellite products with in situ measurements was carried out throughout the entire annual cycle of phytoplankton development. For this purpose, a data array containing the results of field and satellite measurements was created.

Chlorophyll $\boldsymbol{a}$ concentration $\left(C_{a}\right)$. The $C_{a-s}$ calculation error in winter averaged $\pm 38 \%$. Deviations from the results of field measurements were observed both towards higher and towards lower values (Fig. 1,a).

A significant deviation of $C_{a-\mathrm{s}}$ values from the results of $C_{a-\mathrm{i}}$ field measurements was noted in spring. The error nature is clearly expressed: at high values of $C_{a-\mathrm{i}}\left(C_{a-}\right.$ i $>1.1 \mathrm{mg} \cdot \mathrm{m}^{-3}$ ) $C_{a-\mathrm{s}}$ was $1.0-5.4$ times lower than $C_{a-\mathrm{i}}$. The error in determining $C_{a-\mathrm{s}}$ in spring averaged $\pm 35 \%$.

In summer, the nature of the error changed: there was primarily an excess of $C_{a-}$ s values compared to $C_{a-\mathrm{i}}$ by $0.36-2.7$ times, by 1.4 times on average. The $C_{a}$ values are small, but the error in $C_{a-s}$ calculation was quite significant $\pm 55 \%$ on average.

${ }^{4}$ NASA Goddard Space Flight Center, 2020. Ocean Level-2 Data Format Specification. [online] Available at: https://oceancolor.gsfc.nasa.gov/docs/format/l2nc/ [Accessed: 21 October 2020].

${ }^{5}$ NASA Goddard Space Flight Center, 2020. The Official NASA/OB.DAAC Data Analysis Software. [online] Available at: https://seadas.gsfc.nasa.gov/ [Accessed: 21 October 2020]. 
a)
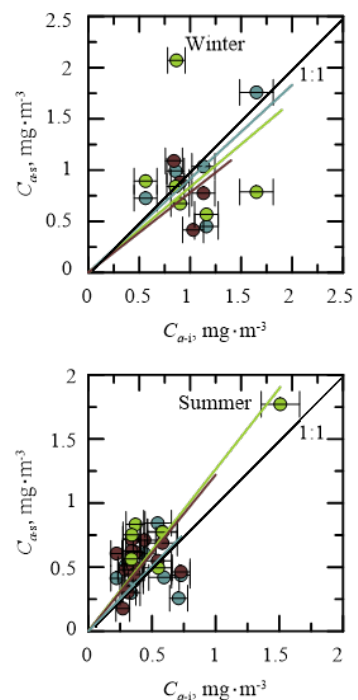

b)
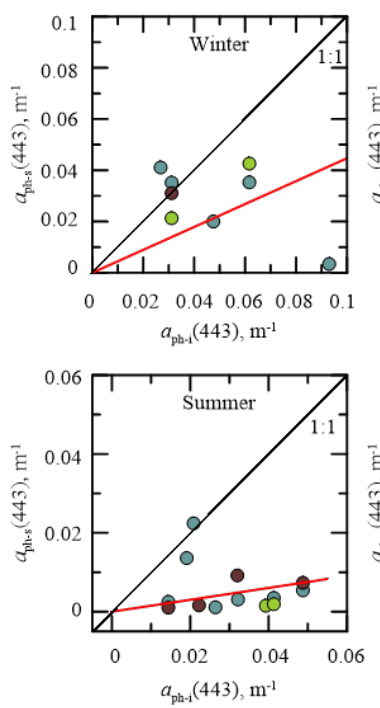
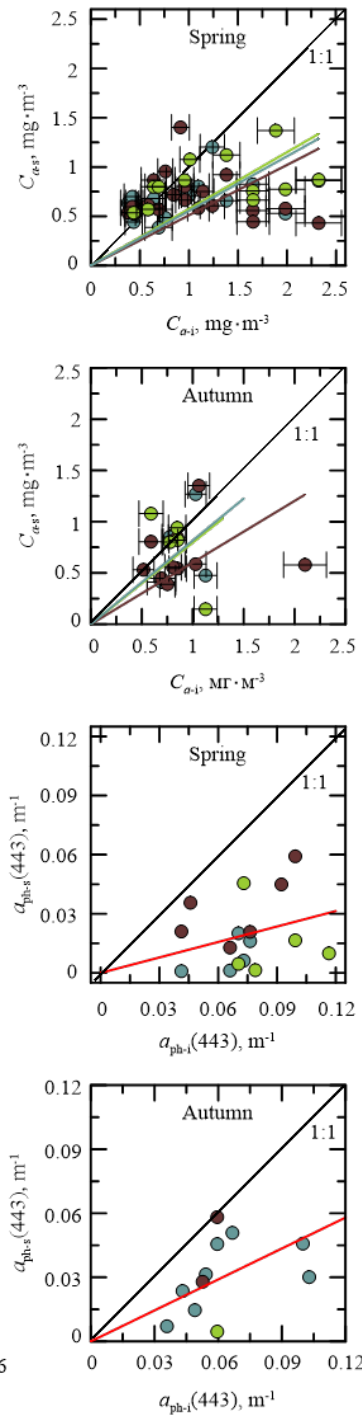

Winter

MA: $n=5, R^{2}=0.91$

$\mathrm{MT}: n=4, R^{2}=0.86$

$\mathrm{V}: n=6, R^{2}=0.65$

\section{Spring}

MA: $n=17, R^{2}=0.79$

MT: $n=20, R^{2}=0.68$

$\mathrm{V}: n=12, R^{2}=0.84$

Summer

MA: $n=12, R^{2}=0.79$

MT: $n=13, R^{2}=0.86$

$\mathrm{V}: n=6, R^{2}=0.94$

Autumn

MA: $n=4, R^{2}=0.83$

MT: $n=10, R^{2}=0.73$

$\mathrm{V}: n=5, R^{2}=0.69$

- MODIS-Aqua (MA)

- MODIS-Terra (MT)

- VIIRS Suomi-NPP (V)

Winter

$n=8, R^{2}=0.57$

Spring

$n=10, R^{2}=0.57$

Summer

$n=13, R^{2}=0.36$

Autumn

$n=11, R^{2}=0.80$

F i g. 1. Comparison of the satellite-derived products $C_{a-\mathrm{s}}(a)$ and $a_{\mathrm{ph}-\mathrm{s}}(443)(b)$ with the results of field bio-optical measurements $\left(C_{\mathrm{a}-\mathrm{i}}\right.$ and $\left.a_{\mathrm{ph}-\mathrm{i}}(443)\right)$. Color lines are the linear regression lines; red line is the linear regression for all the spectroradiometers

In autumn, as well as in spring, $C_{a-\mathrm{s}}<C_{a-\mathrm{i}}$ (when $C_{a-\mathrm{i}}>1.1 \mathrm{mg} \cdot \mathrm{m}^{-3}$ ), mainly according to $M T$ data. The error in $C_{a-s}$ determination from the data of all spectroradiometers in that season averaged $\pm 36 \%$.

That is, throughout the year, the $C_{a-s}$ satellite product is determined with a large relative error (on average $\pm 41 \%$ ) according to the data of all spectroradiometers, but it is still possible to single out $V$ (an average error of $\pm 43 \%$ with a sample of 29 values) as the most inaccurate of the considered spectroradiometers and $M A$ as the best one (error on average $\pm 38 \%$ with a sample of 38 values).

The satellite product $C_{a-s}$ is generated by two algorithms: $C I$ and OCx. For $C_{a-s}$ below $0.15 \mathrm{mg} \cdot \mathrm{m}^{-3}$, the $C I$ algorithm is used, for $C_{a-\mathrm{s}}$ above $0.20 \mathrm{mg} \cdot \mathrm{m}^{-3}$ - the $O C x$ 
algorithm is applied. With $C_{a-s}$ values ranging from 0.15 to $0.20 \mathrm{mg} \cdot \mathrm{m}^{-3}$, the $C I$ and $O C x$ algorithms are combined using a balanced approach. Input data for $C_{a-s}$ generated by $C I$ and $O C x$ algorithms are the values of the remote sensing reflectance $\left(R_{\mathrm{rs}}(\lambda)\right)$. Except $R_{\mathrm{rs}}(\lambda)$, the $O C x$ algorithm includes constant table coefficients $a_{i}$.

Use of the same coefficients without taking into account the type of water can be one of the reasons for the occurrence of an error in $C_{a-s}$ determining at the regional level.

Light absorption by phytoplankton at $443 \mathrm{~nm}$. This coefficient values, obtained from the data of spectroradiometers ( $\left.a_{\mathrm{ph}-\mathrm{s}}(443)\right)$, during the year is almost always lower than the results of in situ observations ( $\left.a_{\mathrm{ph}-\mathrm{s}}(443)\right)$. Ranges of $a_{\mathrm{ph}-\mathrm{s}}$ (443) variation are, on average, two times narrower than the range of variation of $a_{\mathrm{ph}}$ s (443) (Fig. 1, b). Thus, the light absorption by phytoplankton in the coastal Black Sea waters, generated by standard algorithms from satellite data, is significantly underestimated.

Relationship between $C_{\boldsymbol{a}}$ and $\boldsymbol{a}_{\mathrm{ph}}$ (443). Earlier, for a large array of ocean data, a relationship between $C_{a}$ and $a_{\mathrm{ph}}(\lambda)$ described by a power function [16, 17] was established. The coefficients of this power-law dependence are different both for various water areas $[18,19]$ and for one water area in different seasons $[20,21]$.

Relationship between $C_{a}$ and $a_{\mathrm{ph}}(\lambda)$ makes it possible to fairly accurately simulate $C_{a}$ in terms of light absorption, taking into account the seasonal characteristics of the influence of phytoplankton habitat conditions on the pigment content and light absorption capacity of cells. This approach which consists in the $C_{a}$ estimation based on $a_{\mathrm{ph}}(\lambda)$, is used in the currently actively developing three-channel algorithm [22].

If $C_{a}$ and $a_{\mathrm{ph}}(\lambda)$ are determined correctly, then their relationship should be traced. Fig. 2 shows that the power-law dependence between the data of field observations ( $a_{\mathrm{ph}-\mathrm{i}}(443)$ and $C_{a-\mathrm{i}}$ ) is observed in all seasons, while the relationship between satellite products $\left(a_{\mathrm{ph}-\mathrm{s}}(443)\right.$ and $\left.C_{a-\mathrm{s}}\right)$ is almost absent, which indicates the incorrectness of these parameters estimates according to the standard NASA algorithms.
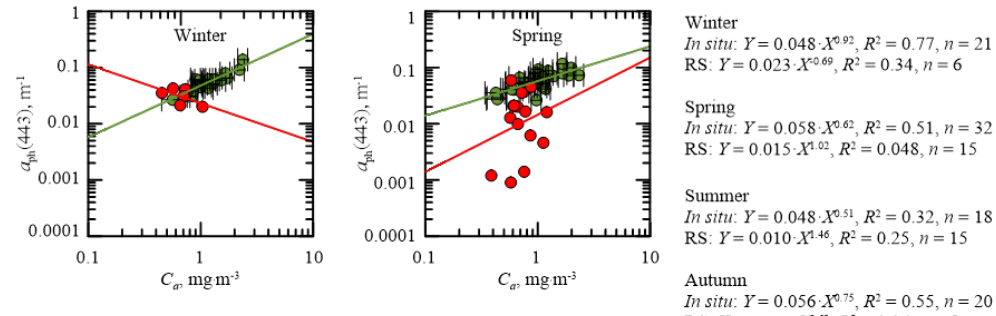

Autumn
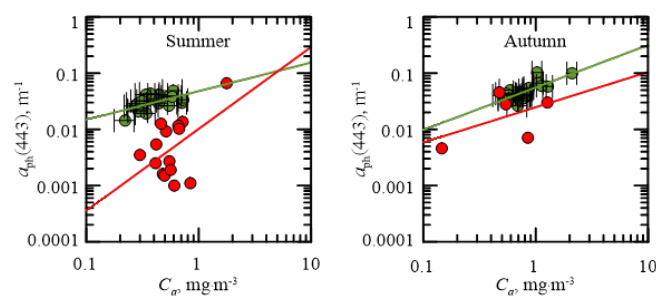
In situ: $Y=0.056 \cdot X^{0.75}, R^{2}=0.55, n=20$
RS: $Y=0.025 \cdot X^{0.63}, R^{2}=0.26, n=5$

- In situ

- Remote Sensing (RS)

F i g. 2. Relation between $a_{\mathrm{ph}}(443)$ and $C_{a}$. Color lines denote the regression lines

Light absorption by colored detrital matter at $443 \mathrm{~nm}$. Range of $a_{\mathrm{CDM}}$ s(443) variability (from 0.010 to $1.02 \mathrm{~m}^{-1}$ ) during the year is five times greater than PHYSICAL OCEANOGRAPHY VOL. 28 ISS. 2 (2021) 
the range of $a_{\text {CDM-s }}(443)$ variability (from 0.060 to $0.23 \mathrm{~m}^{-1}$ ) (Fig. 3, a). Error of $a_{\text {CDM-s }}(443)$ determination averaged $\pm 160 \%$ per year. The smallest errors were observed in spring: the mean relative error of $a_{\mathrm{CDM}-\mathrm{s}}$ (443) determination was $\pm 82 \%$.
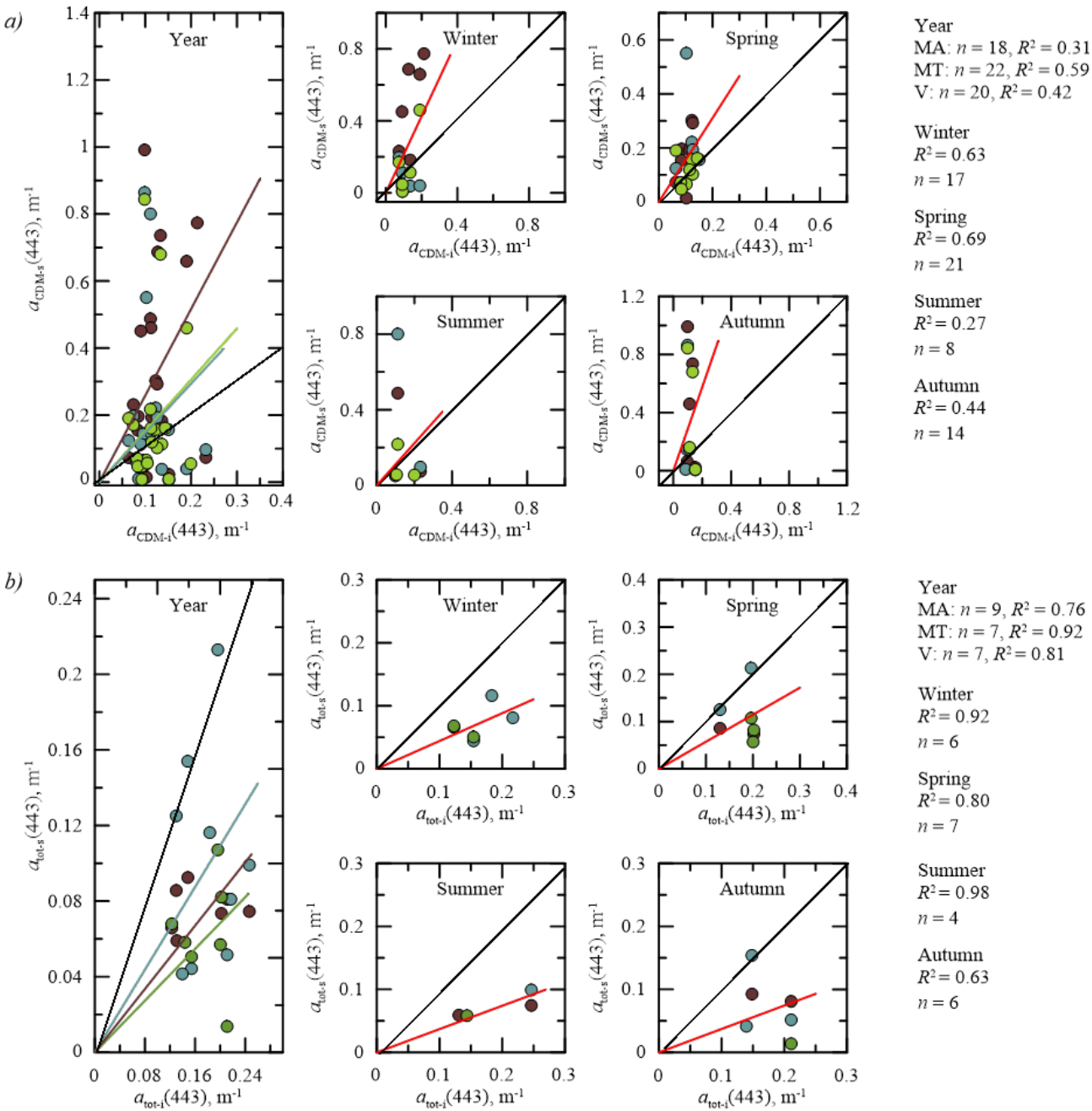

Year

MA: $n=9, R^{2}=0.76$

MT: $n=7, R^{2}=0.92$

$\mathrm{V}: n=7, R^{2}=0.81$

Winter

$R^{2}=0.92$

$n=6$

Spring

$R^{2}=0.80$

$n=7$
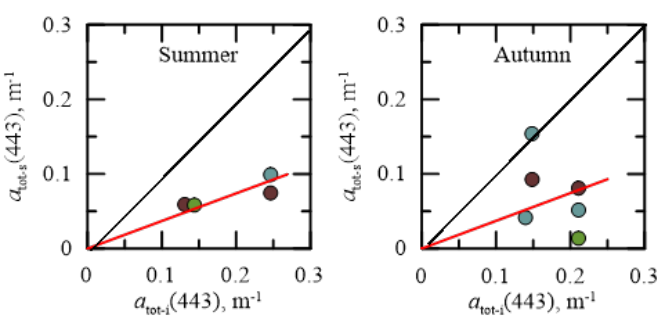

Summer

$R^{2}=0.98$

$n=4$

Autumn

$R^{2}=0.63$

$n=6$

F i g. 3. Comparison of the $a_{\mathrm{CDM}-\mathrm{s}}(443)(a)$ and $a_{\mathrm{tot}-\mathrm{s}}(443)(b)$ values with the results of field measurements ( $a_{\mathrm{CDM}-\mathrm{i}}(443)$ and $\left.a_{\mathrm{tot}-\mathrm{i}}(443)\right)$. Designations as in Fig. 1

The satellite products reconstructed from the data of quasi-synchronous measurements by various spectroradiometers were different, but on the whole, the accuracy of determining satellite products throughout the year was comparable: the relative error $\delta\left(\mathrm{C}_{\mathrm{a}-\mathrm{s}}\right)$ was $\pm 38, \pm 41, \pm 43 \%$ for $M A ; M T$; $V$, respectively, and $\left(a_{\mathrm{ph}-}\right.$ s $(443)) \pm 64, \pm 54, \pm 75 \%$, with the exception of $\delta\left(a_{\mathrm{CDM}-\mathrm{s}}(443)\right)$ equal to $\pm 158, \pm 207$, $\pm 117 \%$.

Light absorption by all OACs at $443 \mathrm{~nm}\left(\boldsymbol{a}_{\mathrm{tot}}(\mathbf{4 4 3})\right)$. Error in $C_{a-\mathrm{s} s}, a_{\mathrm{ph}-\mathrm{s}}(443)$ and $a_{\mathrm{CDM}-\mathrm{s}}(443)$ determination is possibly a consequence of the incorrect separation of the 
total light absorption by all OACs into $a_{\mathrm{ph-s}}(443)$ and $a_{\mathrm{CDM}-\mathrm{s}}(443)$. To test this hypothesis, $a_{\text {tot }}(443)$ values from spectroradiometer data and in situ measurements were compared. The light absorption by pure water at $443 \mathrm{~nm}\left(a_{\mathrm{w}}(443), \mathrm{m}^{-1}\right)$ was not taken into account, since it is constant.

Throughout the year, the difference between the maximum and minimum values according to satellite data $\left(0.014-0.21 \mathrm{~m}^{-1}\right)$ and according to in situ measurements $\left(0.051-0.25 \mathrm{~m}^{-1}\right)$ was the same and amounted to $0.20 \mathrm{~m}^{-1}$. At the same time, the range of satellite values was slightly shifted (by $0.037 \mathrm{~m}^{-1}$ ) relative to the in situ data towards smaller values (Fig. 3, $b$ ).

However, it should be noted that the data comparison in pairs of quasisynchronous measurements showed that $a_{\text {tot-s }}(443)$ is $0.92-4.1$ times lower than $a_{\text {tot-i }}(443)$. In one case, a significant difference was found between satellite ( $V$ ) data $\left(a_{\text {tot-s }}(443)=0.014 \mathrm{~m}^{-1}\right)$ from the results of in situ observations $\left(a_{\text {tot-i }}(443)=\right.$ $=0.21 \mathrm{~m}^{-1}$ ). Comparison of all pairs of data revealed that the values of $a_{\text {tot-s }}(443)$ do not coincide with $a_{\text {tot-i }}(443)$. In this case, according to the data of different spectroradiometers obtained within one day the $a_{\text {tot-s }}(443)$ values differ significantly (in 0.57-7.2 times) among themselves. Hence, it follows that the problem lies not in the accuracy of $a_{\text {tot-s }}(\lambda)$ dividing into the light absorption indices of the OAC (by phytoplankton and colored dissolved organic matter in total with the non-algal particles), but in its initially inaccurate determination. Comparison showed that the $a_{\text {tot-s }}(443)$ estimate is lower than $a_{\text {tot-i }}(443)$ in most cases $(0.92-15$ times, on average 2.9 times).

The OAC contribution to total light absorption according to in situ measurements. Relative contribution of individual OACs to the total light absorption varies depending on the wavelength and season and characterizes the optical type of waters [23-26]. The OAC contribution to the total light absorption $\left(a_{\text {tot-i }}(\lambda)\right)$ at 440 and $488 \mathrm{~nm}$ in individual seasons in the surface sea layer is shown in Fig. 4.

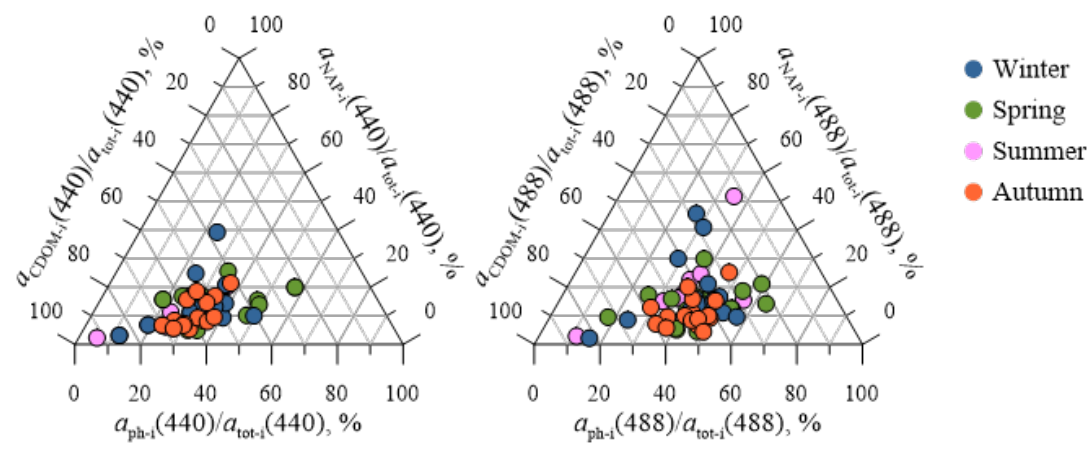

F i g. 4. Contribution of the phytoplankton $\left(a_{\mathrm{ph}-\mathrm{i}}(\lambda) / a_{\mathrm{tot}-\mathrm{i}}(\lambda)\right)$, the colored dissolved organic matter $\left(a_{\mathrm{C}-}\right.$ DOM-i $\left.(\lambda) / a_{\text {tot-i }}(\lambda)\right)$, and the non-algal particles $\left(a_{\text {NAP-i }}(\lambda) / a_{\text {tot- }}(\lambda)\right)$ to the light absorption budget $\left(a_{\text {tot-i }}(\lambda)\right)$ at $440 \mathrm{~nm}$ and $488 \mathrm{~nm}$

For the studied wavelengths, it was found that the light absorption by colored dissolved organic matter prevails over the light absorption by phytoplankton and the light absorption by non-algal particles in all seasons. Throughout the year, the largest contribution of colored dissolved organic matter was noted in autumn. On average, its value was 59 and $47 \%$ at 440 and $488 \mathrm{~nm}$, respectively. At $488 \mathrm{~nm}$, the PHYSICAL OCEANOGRAPHY VOL. 28 ISS. 2 (2021) 
contribution of phytoplankton to total absorption increases in comparison with the data obtained at $440 \mathrm{~nm}$. Analysis of seasonal dynamics showed that the largest contribution of phytoplankton to the total absorption occurs in spring and averages 35 and $44 \%$ at 440 and $488 \mathrm{~nm}$, respectively. The noted seasonal dynamics of the values of the light absorption indices of individual OAC of the medium, as well as their relative contribution to the total light absorption at wavelengths in the radiance range in which the sea brightness is most sensitive to the optical properties of the medium, is probably the cause of gross errors in the OAC estimate using standard algorithms.

The study showed that the considered satellite products incorrectly correlate with the bio-optical indicators of the waters of the considered water area and their ratios (table). Seasonal variation of chlorophyll $a$ concentration is smoothed out: the $C_{a-\mathrm{s}}$ values vary from $0.18-1.8 \mathrm{mg} \cdot \mathrm{m}^{-3}$ in summer to $0.39-1.4 \mathrm{mg} \cdot \mathrm{m}^{-3}$ in spring, in contrast to the naturally observed increase in $C_{a-\mathrm{i}}$ from minimum values $(0.22-$ $\left.1.5 \mathrm{mg} \cdot \mathrm{m}^{-3}\right)$ in summer to maximum $\left(0.38-2.3 \mathrm{mg} \cdot \mathrm{m}^{-3}\right)$ in spring. The $C_{a-\mathrm{s}}$ error, depending on the season, varied from \pm 34 to $\pm 55 \%$, while it was not of the same type: in spring, the $C_{a-\mathrm{s}}$ values were on average 1.6 times lower than $C_{a-\mathrm{i}}$, and 1.4 times higher in summer.

Ratio of light absorption by the phytoplankton to absorption by the colored detrital matter at $443 \mathrm{~nm}\left(a_{\mathrm{ph}}(443) / a_{\mathrm{CDM}}(443)\right)$

\begin{tabular}{|c|c|c|c|c|}
\hline Value & in situ & $M A$ & $M T$ & $V$ \\
\hline \multicolumn{5}{|c|}{ Winter } \\
\hline Min & $12 / 88$ & $3.0 / 97$ & - & $31 / 69$ \\
\hline Max & $51 / 49$ & $80 / 20$ & - & $84 / 16$ \\
\hline Mean & $32 / 68$ & $38 / 62$ & $50 / 50^{*}$ & $58 / 42$ \\
\hline \multicolumn{5}{|c|}{ Spring } \\
\hline Min & $20 / 80$ & $1.0 / 99$ & $7,0 / 93$ & $2 / 98$ \\
\hline Max & $58 / 42$ & $15 / 85$ & $81 / 19$ & $60 / 40$ \\
\hline Mean & $38 / 62$ & $9.0 / 91$ & $36 / 64$ & $21 / 79$ \\
\hline \multicolumn{5}{|c|}{ Summer } \\
\hline Min & $6.0 / 94$ & $1 / 99$ & $0.40 / 100$ & $3.0 / 97$ \\
\hline Max & $37 / 63$ & $14 / 86$ & $16 / 84$ & $55 / 45$ \\
\hline Mean & $26 / 71$ & 7.0/93 & 8.0/92 & $18 / 82$ \\
\hline \multicolumn{5}{|c|}{ Autumn } \\
\hline Min & $24 / 76$ & $5.0 / 95$ & $30 / 70$ & - \\
\hline Max & $39 / 61$ & $88 / 12$ & $88 / 12$ & - \\
\hline Mean & $33 / 67$ & $45 / 55$ & $51 / 49$ & $34 / 66^{*}$ \\
\hline
\end{tabular}

* One data pair. 
Inaccuracy in the chlorophyll a concentration determination leads to errors in the determination of many other indicators, the calculations of which are based on this parameter. In particular, this leads to an incorrect estimate of the phytoplankton biomass, primary production and growth rate of plankton microalgae [27, 28]. The $a_{\text {CDM-s }}(443)$ values are higher than the $a_{\text {ph-s }}$ (443) values (2.2 times on average), and the $a_{\mathrm{ph}-\mathrm{s}}(443)$ values are lower than the $a_{\mathrm{ph}-\mathrm{i}}$ (443) (9 times on average) throughout the year, leading to an incorrect result of calculating the relative contribution of phytoplankton and non-algal particles of optically active substances in the medium (CDOM and NAP), and, consequently, to an error in determining the optical properties of waters, in particular transparency, spectral properties of quantum irradiation penetrating into the water column [4, 24, 29] and photosynthetic potential of microalgae [30-32].

The results of the study indicate that the applied standard algorithms based on bio-optical indicators of Case 1 water [33] are not suitable for calculating satellite products for the coastal Black Sea (in particular, in the area of the Sevastopol Bay).

To use remote sensing data, it is necessary to develop regional algorithms that take into account the seasonal features of the spectral bio-optical indicators of waters and their relationship with the concentration of the main photosynthetically active pigment, chlorophyll $a$, in the region under consideration. In particular, it is possible to adapt the three-channel algorithm [22], which divides the total light absorption into the absorption of the colored dissolved organic matter in the sum with non-algal particles and absorption by phytoplankton. In the calculation by this algorithm, the remote sensing reflectance at 480-560 $\mathrm{nm}$ are used, according to which the concentration of chlorophyll $a$ is restored, taking into account the relationship between the light absorption by phytoplankton and the chlorophyll $a$ concentration $[20,34]$.

\section{Conclusion}

Based on the formed long-term array of natural bio-optical data, the accuracy of satellite products generated from the data of the $M A, M T$ and $V$ spectroradiometers was estimated. The following results were obtained:

1. On average, the relative error of the standard satellite product "chlorophyll $a$ concentration", depending on the season, ranged from \pm 34 to $\pm 55 \%$, while the error was not of the same type: in spring, the $C_{a-\mathrm{s}}$ values were on average 1.6 times below $C_{a-\mathrm{i}}$, and in summer -1.4 times higher.

2. During the study, it was revealed that when calculating satellite products using standard NASA algorithms, the contribution of phytoplankton to total light absorption remains underestimated: on average, the values of light absorption by phytoplankton at $443 \mathrm{~nm}\left(a_{\mathrm{ph}-\mathrm{s}}(443)\right)$ were nine times less than the results of field measurements. At the same time, the light absorption of colored dissolved organic matter in total with the non-algal particles at $443 \mathrm{~nm}\left(a_{\mathrm{CDM}-\mathrm{s}}(443)\right)$ was, on average, 2.2 times overestimated.

3. Significant errors in the calculation of satellite products and the difference between the light absorption values of all OACs of water $\left(a_{\mathrm{tot}}(\lambda)\right)$ cast doubt on the applicability of standard algorithms for the sea area under study.

4. Distribution of the OAC contribution to the total light absorption varies throughout the year: the largest $C D O M$ contribution at 443 and $488 \mathrm{~nm}$ (59 and 47\%) occurs in autumn, and the largest $a_{\mathrm{ph}-\mathrm{i}}(\lambda)$ contribution (35 and 43\%) - in the spring. 


\section{REFERENCES}

1. $\quad$ Oguz, T., Ed., 2008. State of the Environment of the Black Sea (2001 - 2006/7). Publications of the Commission on the Protection of the Black Sea against Pollution (BSC) 2008-3. Istanbul, Turkey, 2008. 448 p.

2. Kopelevich, O.V., Sheberstov, S.V., Yunev, O., Basturk, O., Finenko, Z.Z., Nikonov, S. and Vedernikov, V.I., 2002. Surface Chlorophyll in the Black Sea over 1978-1986 Derived from Satellite and In Situ Data. Journal of Marine Systems, 36(3-4), pp. 145-160. doi:10.1016/s0924-7963(02)00184-7

3. Jerlov, N.G., 1976. Marine Optics. Amsterdam: Elsevier, 230 p.

4. Kirk, J.T.O., 2010. Light and Photosynthesis in Aquatic Ecosystems. $3^{\mathrm{d}}$ ed. Cambridge: Cambridge University Press, 662 p. https://doi.org/10.1017/CBO9781139168212

5. Gordon, H.R. and Wang, M., 1994. Retrieval of Water-Leaving Radiance and Aerosol Optical Thickness over the Oceans with SeaWiFS: A Preliminary Algorithm. Applied Optics, 33(3), pp. 443-452. doi:10.1364/ao.33.000443

6. Skorokhod, E.Yu., Efimova, T.V., Moiseeva, N.A., Zemlianskaia, E.A., Churilova, T.Ya. and Suslin, V.V., 2019. [Comparison of Standard Products from MODIS Aqua/Terra and VIIRS Spectroradiometers with the Results of Bio-Optical Measurements in the Coastal Waters of Sevastopol]. In: IBSS, 2019. Pontus Euxinus - 2019: Proceedings of XI All-Russian Scientific and Applied Conference for Young Scientists on the Water Systems Problems, Dedicated to the Remembrance of Prof. S. B. Gulin, Sevastopol, 23-27 September, 2019. Sevastopol: IBSS, pp. 134-135 (in Russian).

7. Jeffrey, S.W. and Humphrey, G.F., 1975. New Spectrophotometric Equations for Determining Chlorophylls a, b, c1 and c2 in Higher Plants, Algae and Natural Phytoplankton. Biochemie und Physiologie der Pflanzen, 167(2), pp. 191-194.

8. $\quad$ Roesler, C.S., 2018. In Situ Bio-Optical Observations on NERACOOS Buoy A01 (2005-2017): multichannel calibrated chlorophyll fluorescence, turbidity, and multispectral incident irradiance and upwelling radiance. Boston : Massachusetts Water Resources Authority. Report 2018-02, 19 p.

9. IOCCG, 2018. IOCCG Ocean Optics and Biogeochemistry Protocols for Satellite Ocean Colour Sensor Validation. Volume 1.0: Inherent Optical Property Measurements and Protocols: Absorption Coefficient. Dartmouth, NS, Canada: IOCCG, 78 p. http://dx.doi.org/10.25607/OBP-119

10. Kishino, M., Takahashi, M., Okami, N. and Ichimura, S., 1985. Estimation of the Spectral Absorption Coefficients of Phytoplankton in the Sea. Bulletin of Marine Science, 37(2), pp. 634642.

11. Tassan, S. and Ferrari, G.M., 1995. An Alternative Approach to Absorption Measurements of Aquatic Particles Retained on Filters. Limnology and Oceanography, 40(8), pp. 1358-1368. https://doi.org/10.4319/lo.1995.40.8.1358

12. O’Reilly, J.E., Maritonera, S., Mitchell, B.G., Siegel, D.A., Carder, K.L., Garver, S.A., Kahru, M. and McClain, C., 1998. Ocean Color Chlorophyll Algorithms for SeaWiFS. Journal of Geophysical Research: Oceans, 103(C11), pp. 24937-24953. https://doi.org/10.1029/98JC02160

13. Hu, C., Lee, Z. and Franz, B., 2012. Chlorophyll a Algorithms for Oligotrophic Oceans: A Novel Approach Based on Three-Band Reflectance Difference. Journal of Geophysical Research: Oceans, 117(C1), C01011. doi:10.1029/2011JC007395

14. Werdell, P.J., Franz, B.A., Lefler, J.T., Robinson, W.D. and Boss, E., 2013. Retrieving Marine Inherent Optical Properties from Satellites Using Temperature and Salinity-Dependent Backscattering by Seawater. Optics Express, 21(26), pp. 32611-32622. doi:10.1364/OE.21.032611 
15. Werdell, P.J., Franz, B.A., Bailey, S.W., Feldman, G.C., Boss, E., Brando, V.E., Dowell, M., Hirata, T., Lavender, S.J. [et al.], 2013. Generalized Ocean Color Inversion Model for Retrieving Marine Inherent Optical Properties. Applied Optics, 52(10), pp. 2019-2037. http://doi.org/10.1364/ao.52.002019

16. Bricaud, A., Babin, M., Morel, A. and Claustre, H., 1995. Variability in the Chlorophyll-Specific Absorption Coefficients of Natural Phytoplankton: Analysis and Parameterization. Journal of Geophysical Research: Oceans, 100(C7), pp. 13321-13332. https://doi.org/10.1029/95JC00463

17. Bricaud, A., Morel, A., Babin, M., Allali, K. and Claustre, H., 1998. Variations of Light Absorption by Suspended Particles with Chlorophyll $a$ Concentration in Oceanic (case 1) Waters: Analysis and Implications for Bio-Optical Models. Journal of Geophysical Research: Oceans, 103(C13), pp. 31033-31044. https://doi.org/10.1029/98JC02712

18. Cleveland, J.S., 1995. Regional Models for Phytoplankton Absorption as a Function of Chlorophyll a Concentration. Journal of Geophysical Research: Oceans, 100(C7), pp. 1333313344. https://doi.org/10.1029/95JC00532

19. Naik, P., D’Sa, E.J., Gomes, H.R., Goés, J.I. and Mouw, C.B., 2013. Light Absorption Properties of Southeastern Bering Sea Waters: Analysis, Parameterization and Implications for Remote Sensing. Remote Sensing of Environment, 134, pp. 120-134. doi:10.1016/j.rse.2013.03.004

20. Churilova, T., Suslin, V., Krivenko, O., Efimova, T., Moiseeva, N., Mukhanov, V. and Smirnova, L., 2017. Light Absorption by Phytoplankton in the Upper Mixed Layer of the Black Sea: Seasonality and Parameterization. Frontiers in Marine Science, 4, 90. https://doi.org/10.3389/fmars.2017.00090

21. Efimova, T., Churilova, T., Moiseeva, N., Zemlianskaia, E., Krivenko, O. and Sakhon, E., 2018. Dynamics in Pigment Concentration and Light Absorption by Phytoplankton, Non-Algal Particles and Colored Dissolved Organic Matter in the Black Sea Coastal Waters (near Sevastopol). Proceedings of SPIE, 10833: 24 $4^{\text {th }}$ International Symposium on Atmospheric and Ocean Optics: Atmospheric Physics, 108336C. doi:10.1117/12.2504657

22. Suslin, V. and Churilova, T., 2016. A Regional Algorithm for Separating Light Absorption by Chlorophyll- $a$ and Coloured Detrital Matter in the Black Sea, Using 480-560 nm Bands from Ocean Colour Scanners. International Journal of Remote Sensing, 37(18), pp. 4380-4400. doi:10.1080/01431161.2016.1211350

23. Robinson, C.M., Cherukuru, N., Hardman-Mountford, N.J., Everett, J.D., McLaughlin, M.J., Davies, K.P., Van Dongen-Vogels, V., Ralph, P.J. and Dobin, M.A., 2017. Phytoplankton Absorption Predicts Patterns in Primary Productivity in Australian Coastal Shelf Waters. Estuarine, Coastal and Shelf Science, 192, pp. 1-16. https://doi.org/10.1016/j.ecss.2017.04.012

24. Churilova, T., Moiseeva, N., Efimova, N., Suslin, V., Krivenko, O. and Zemlianskaia, E., 2017. Annual Variability in Light Absorption by Particles and Colored Dissolved Organic Matter in the Crimean Coastal Waters (the Black Sea). Proceedings of SPIE, 10466: $23^{\text {rd }}$ International Symposium on Atmospheric and Ocean Optics: Atmospheric Physics, 104664B. doi:10.1117/12.2288339

25. Darecki, M., Weeks, A., Sagan, S., Kowalczuk, P. and Kaczmarek, S., 2003. Optical Characteristics of Two Contrasting Case 2 Waters and Their Influence on Remote Sensing Algorithms. Continental Shelf Research, 23(3-4), pp. 237-250. https://doi.org/10.1016/s02784343(02)00222-4

26. Bricaud, A., Babin, M., Claustre, H., Ras, J. and Tièche, F., 2010. Light Absorption Properties and Absorption Budget of Southeast Pacific Waters. Journal of Geophysical Research: Oceans, 115(C8), C08009. doi:10.1029/2009JC005517 
27. Campbell, J., Antoine, D., Armstrong, R., Arrigo, K., Balch, W., Barber, R., Behrenfeld, M., Bidigare, R., Bishop, J. [et al.], 2002. Comparison of Algorithms for Estimating Ocean Primary Production from Surface Chlorophyll, Temperature, and Irradiance. Global Biogeochemical Cycles, 16(3), pp. 9-1-9-15. doi:10.1029/2001GB001444

28. Krivenko, O.V., Parkhomenko, A.V., Churilova, T.Ya., Finenko, Z.Z. and Suslin, V.V., 2012. Reanalysis of Long Term Changes in the Phytoplankton Biomass in the Open Part of the Black Sea Based on In Situ Measurements and Satellite Observations. In: MHI, 2012. Ekologicheskaya Bezopasnost' Pribrezhnykh i Shel'fovykh Zon i Kompleksnoe Ispol'zovanie Resursov Shel'fa [Ecological Safety of Coastal and Shelf Zones and Comprehensive Use of Shelf Resources]. Sevastopol: ECOSI-Gidrofizika. Iss. 26(2), pp. 185-194 (in Russian).

29. Harvey, E.T., Walve, J., Andersson, A., Karlson, B. and Kratzer, S., 2019. The Effect of Optical Properties on Secchi Depth and Implications for Eutrophication Management. Frontiers in Marine Science, 5, 496. doi:10.3389/fmars.2018.00496

30. Markager, S. and Vincent, W.F., 2001. Light Absorption by Phytoplankton: Development of a Matching Parameter for Algal Photosynthesis under Different Spectral Regimes. Journal of Plankton Research, 23(12), pp. 1373-1384. https://doi.org/10.1093/plankt/23.12.1373

31. Bracher, A.U. and Tilzer, M.M., 2001. Underwater Light Field and Phytoplankton Absorbance in Different Surface Water Masses of the Atlantic Sector of the Southern Ocean. Polar Biology, 24(9), pp. 687-696. https://doi.org/10.1007/s003000100269

32. Churilova, T.Ya., Suslin, V.V., Moiseeva, N.A. and Efimova, T.V., 2020. Phytoplankton Bloom and Photosynthetically Active Radiation in Coastal Waters. Journal of Applied Spectroscopy, 86(6), pp. 1084-1091. https://doi.org/10.1007/s10812-020-00944-0

33. Morel, A. and Prieur, L., 1977. Analysis of Variations in Ocean Color. Limnology and Oceanography, 22(4), pp. 709-222. https://doi.org/10.4319/lo.1977.22.4.0709

34. Churilova, T., Suslin, V., Sosik, H.M., Efimova, T., Moiseeva, N., Moncheva, S., Mukhanov, V., Rylkova, O. and Krivenko, O., 2018. Phytoplankton Light Absorption in the Deep Chlorophyll Maximum Layer of the Black Sea. European Journal of Remote Sensing, 52(sup. 1), pp. 123-136. doi:10.1080/22797254.2018.1533389

About the authors:

Elena Yu. Skorokhod, Junior Research Associate, Geomatics Research Center, A.O. Kovalevsky Institute of Biology of the Southern Seas, Russian Academy of Sciences (2 Nakhimov Ave., Sevastopol, 299011, Russian Federation) ORCID ID: 0000-0002-3057-3964, Scopus Author ID: 57215009764, ResearcherID: A-6831-2019, Author ID: 1034485, SPIN-code: 3314-5775, elenaskorokhod@ibss-ras

Tatiana Ya. Churilova, Senior Scientist, Head of Geomatics Research Center, A.O. Kovalevsky Institute of Biology of the Southern Seas, Russian Academy of Sciences (2 Nakhimov Ave., Sevastopol, 299011, Russian Federation), Ph. D. (Biol.), ORCID ID: 0000-0002-0045-7284, Scopus Author ID: 6603622802, ResearcherID: O-8437-2016, Author ID: 888565 SPIN-code: 2238-9533, tanya.churilova@ibss-ras.ru

Tatiana V. Efimova, Junior Research Associate, Geomatics Research Center, A.O. Kovalevsky Institute of Biology of the Southern Seas, Russian Academy of Sciences (2 Nakhimov Ave., Sevastopol, 299011, Russian Federation), ORCID ID: 0000-0003-3908-4160, Scopus Author ID: 57194423783, ResearcherID: X-1355-2019, Author ID: 766926, SPIN-code: 1668-0742, tefimova@ibss-ras.ru

Nataliia A. Moiseeva, Junior Research Associate, Geomatics Research Center, A.O. Kovalevsky Institute of Biology of the Southern Seas, Russian Academy of Sciences (2 Nakhimov Ave., Sevastopol, 299011, Russian Federation), ORCID ID: 0000-0003-1356-7981, Scopus Author ID: 57194431032, ResearcherID: AAH-2819-2019, Author ID: 959717, SPIN-code: 8946-3315, nataliya-moiseeva@yandex.ru 
Vyacheslav V. Suslin, Senior Scientist, Ph. D. (Math.-Phys.), Marine Hydrophysical Institute of RAS (2 Kapitanskaya St., Sevastopol, 299011, Russia), ORCID ID: 0000-0002-8627-7603, Scopus Author ID: 6603566261, ResearcherID: B-4994-2017, AuthorID: 825673 SPIN-code: 1681-7926, slava.suslin@mhi-ras.ru

Contribution of the co-authors:

Elena Yu. Skorokhod - preparation of the article text, collection of materials, data processing and analysis of the results, preparation of graphic materials

Tatiana Ya. Churilova - the problem statement, preparation of the article text

Tatiana V. Efimova - collection of materials, data processing

Nataliia A. Moiseeva - collection of materials, data processing

Vyacheslav V. Suslin - preparation of the article text, consultations on the topic of the article

All the authors have read and approved the final manuscript.

The authors declare that they have no conflict of interest. 